\title{
Racial discrimination: Experiences of black medical school alumni at the University of Cape Town, 1945 - 1994
}

\author{
A M Perez, N Ahmed, L London
}

Objective. Reflecting on its role during apartheid, the Faculty of Health Sciences of the University of Cape Town (UCT) undertook a study to explore the experiences of black alumni who trained in the period 1945 - 1994.

Design. Seventy-five black alumni were selected through purposive and snowball recruitment, resulting in 52 face-to-face and 23 telephonic or postal interviews.

Results. Experiences of racial discrimination were widely reported and respondents believed the quality of their training was adversely affected. Until 1985, black students were required to sign a declaration agreeing to excuse themselves from classes where white patients were present. Black students were denied access to white patients in wards, and the university admitted that it could not guarantee their clinical training. Tutorial groups were racially segregated. Black students were also excluded from university facilities, events and extramural activities. Themes that emerged were: lack of social contact with white staff and students during training, belief that white staff members actively or tacitly upheld discriminatory regulations, and resistance by black students. Efforts of some white staff to resist discrimination were acknowledged.

Conclusion. Racism was entrenched explicitly and implicitly. Perceptions of the attitudes of white staff to apartheid legislation on the part of black alumni were diverse, ranging from claims of active support for racial discrimination to recognition of attempts to resist racist rules. These findings provided the basis for Faculty transformation initiatives based on human rights, respect for human dignity and non-discrimination.

S Afr Med J 2012;102(6):574-577.
Understanding how higher education institutions become a part of society-wide discrimination in South Africa (SA) has implications for training health professionals, ${ }^{1-4}$ given that health institutions and professionals applied discriminatory practices under apartheid. ${ }^{5}$ This concern underpinned research to explore how black alumni, ${ }^{6}$ who attended the Faculty of Health Sciences (FHS) of the University of Cape Town (UCT) before 1994, experienced racial discrimination, how this discrimination affected the core academic mission of the institution, and what future challenges this experience poses for the FHS.

\section{Racial segregation and medical training at UCT}

Before 1948 no formal legislation existed to restrict the admission of black persons into SA universities. However, university policies effectively barred blacks from study. In 1923 UCT's Council declined to admit 'native or coloured' students; and when blacks were eventually admitted into universities, participation in sports and social activities was restricted. ${ }^{7}$ In the Medical Faculty, prior to 1929, black students were denied admission, to avoid mixed classes and 'white patients being examined by black students.' By 1937 a total of 40 coloured and Indian students had been admitted to UCT's Arts, Science, Education, and Medical faculties. However, black medical students could not complete the course, as local hospitals barred access to white patient wards for their clinical training. ${ }^{8}$ When UCT admitted coloured and Indian students for the first time when World War II precluded travelling overseas for training, admission was conditional on signing a declaration that effectively entrenched selfimposed racial exclusion.

Faculty of Health Sciences, University of Cape Town, Cape Town, South Africa A M Perez, MB BDS, M Dent

N Ahmed, MA (Clin Psych)

L London, MB ChB, M Med (PHM), MD
From 1959 to 1985 black students were required to obtain permission from the relevant Minister to attend a 'white' university. The 1983 University Amendment Act replaced the permit system to attend universities with a racially determined quota that universities were required to administer. ${ }^{10}$ Despite this, UCT was instructed not to admit African students to study medicine, and only admitted its first African medical student in $1985^{10,11}$

\section{Methods}

Data were obtained by qualitative and quantitative methods. Pre1994 black alumni were recruited using purposive and snowball sampling. An initial list of potential participants was compiled, and supplemented by interviewee suggestions for others to interview.

Of the 86 alumni contacted, 11 declined to participate. In-depth, semi-structured interviews were conducted with 52 respondents. Where face-to-face interviews were not possible (in 23), respondents were interviewed telephonically.

Open-ended data were analysed using Strauss and Corbin's 'open coding' method. ${ }^{12}$ Analysis reliability was enhanced by a coderecode procedure conducted by one researcher. ${ }^{13}$ No discrepancies were found in this procedure. Coding reliability was confirmed by a comparison of independent coding of 10 pages of transcribed data by 2 researchers.

\section{Results}

Results are presented with 3 themes: (i) discrimination and its impact on medical training, (ii) perceived attitudes of white staff and students, and (iii) black students' resistance to discrimination.

\section{Impact of discrimination}

Most respondents (64\%) believed that the quality of their training was adversely affected by racial discrimination. Black students were prohibited from training with white patients until well into the 1980s. Tutorial groups were racially segregated and respondents believed that the best tutors were assigned to the white student groups. Hospital and university staff actively prevented black students' access to white patient wards; it was not uncommon to encounter a 'guard' 
to enforce this. Segregation was upheld in outpatient departments where patients of all race groups attended: 'In outpatients, where whites and non-whites were seen in the same clinics, we were required to stand outside when a white patient was being seen'

Before 1985, black students had to sign a document confirming that they understood that UCT was unable to guarantee clinical training and to agree to excuse themselves from any class, clinic or demonstration where a white patient (or even dead body) was present. Effectively, this made black students the agents of their own exclusion and humiliation: 'With post-mortems, when they had a white body you had to walk out. It was one of those unspoken, unwritten laws.' 'Applying for permits was a big issue for me. Having to be confined to a certain part of the hospital was another. The indignity was there all the time.'

Black students were barred from university residences, and could not participate in university events, extra-mural activities and social functions. Denied access to residences, many had to seek alternative accommodation, which increased travelling and living expenses for some, forcing them to work part-time for additional income. The impacts on respondents' trust in, and identification with, UCT were enormous. A respondent recounted how he felt 'like an outsider' and had 'little memory of feeling at home or proud of UCT. Respondents' associated these experiences with a strong sense of having been denied opportunities: 'Cheated! There were so many ordinary things we were denied because of our colour. We could have excelled academically as well as in any other spheres, viz, debates, sports, community activities, etc.'

Nonetheless, some respondents acknowledged and retained allegiance to UCT despite being discriminated against, confiding, for example, that they were 'proud of having been at UCT, despite all the problems'. Many acknowledged that the technical quality of their training 'despite negative factors' was 'excellent'. Some noted that training omissions led to missed learning opportunities: 'We didn't see a spectrum of disease that the white students saw, nor got the personal attention they got. We were definitely affected. We weren't even taught how to read an ECG.

Racism reportedly also affected examinations, with oral examination assessments perceived as biased. Some respondents felt they had to work harder than their white counterparts to achieve: 'I remember always feeling that I had not just to be good. I had to be better than good. I wanted to show them that I was equal and better.'

\section{'They could have done more'}

Although most respondents believed that white staff at UCT supported racial discrimination, many acknowledged white staff who put patients and students ahead of upholding apartheid legislation.

White staff's support for discrimination usually took the form of 'silence' and a failure to 'do more', though some explicit discrimination was noted: 'All the academic teaching staff in the clinical years tacitly observed the University's apartheid policies. I don't think that the academic staff were prepared openly to oppose apartheid policies.'

Comments about their white student peers reflected perceptions of a similar range of complicity - from denial of what should have been all students' rights (e.g. black students attending white patient presentations) to a failure to oppose UCT's discriminatory policies, and apathy towards the predicament of black students. One respondent remembered how white students responded to a planned boycott organised by black students: 'We tried to get white students to boycott with us. A few tried, but they said that it wasn't their fault.'

Exclusion was a hallmark of formal academic teaching and the social fabric of university life. This separation became a powerful norm, with few attempts of social integration from either side: 'I can't remember a white student coming to our social functions and viceversa. It was just the accepted way of doing things.'

An important aspect of respondents' experiences was limited social contact with staff, and lack of personal attention compared with their white counterparts. In clinical training, they were denied contact with staff outside of university hours: 'We were always a minority and always felt that we were such. White colleagues would always say what a nice time they had at a lecturer's house or out socialising with them. We were never invited along.'

Entering university was often the first experience of students contact with other racial groups. Common religious identity was an exception that enabled a few white students to cross the racial divide and socialise with black students.

Against this, a few respondents reported that a minority of white staff members and students 'were genuinely concerned by our circumstances' and resisted racist discrimination by offering additional tutorials, held in the staff member's home. Thus, broad generalisations made about white staff members may have been unfair: 'There may have been people with different views. We thought white professors were automatically racist. This was not so, but that was the problem we faced.'

For many respondents, white colleagues' acknowledgements of racism, if expressed at all, was done privately rather than publicly. Several commented that they did not know what white students thought about their involvement in resistance to discrimination; others were uncertain about the nature of interactions that existed between black students and white staff. Besides tensions between black and white students, black students themselves differed in their approach to social interactions. Given the intensely politicised environment at UCT at the time, interaction with white students was considered by some to represent collusion: 'The early '70s was the period of black consciousness. A lot of meetings and discussions were held at the time. Many guys said we mustn't talk to white students. The idea of isolation evoked debate and [strong] feeling. There was an active campaign to isolate two coloured students who associated with white students.'

A few respondents commented on the lack of protest and sometimes passive acceptance of the status quo by black students, raising issues regarding black students' agency in their own oppression: 'To a certain extent we accepted the status quo. We were guilty because we were so involved in our studies.'

Respondents commented on the university's apathy, perceived as paying 'a lot of lip-service.' Despite being a 'liberal university of academic freedom', which purported to being opposed to the apartheid government, many believed that UCT could have improved training conditions for black students. After 1985 some apartheid laws were relaxed, and black students were allowed to examine white patients. Some white patients protested about this, but responses from white staff varied from accession to the patients' prejudices to rejection of patients' racist attitudes. As one respondent pointed out 'They did allow us to go into white wards, but the reception was not always warm.'

\section{Resistance to discrimination}

There was a sense that many white colleagues thought that black students should be passive and grateful for the privilege of studying at UCT. For example, a respondent described the Dean's attitude: 'All first year students met the Dean on main campus. He would greet you and let you know that all black students should be very grateful to be at this "illustrious" institution.'

However, the late-1960s saw the beginning of student resistance with boycotts of postmortems, graduation, class photographs, and final-year celebrations. It was an era where formal complaints were 
laid with UCT authorities. Black students began defying the 'rules' and entered white wards and other 'forbidden' areas, such as the cafeteria and students' union.

Some black students expressed a different form of protest by refusing to accept racially defined Faculty awards: 'I qualified and got good marks in Paediatrics. The prize I got said I was the best coloured student. I gave it back'.

There was resistance linked to wider anti-apartheid protests, with respondents joining marches during the time of the 1976 Soweto uprising and the killing of medical student and political activist Steve Biko. ${ }^{1}$ One protesting black postgraduate student was arrested, spent 2 weeks in solitary confinement and was dismissed before his specialist exams, only to be reinstated following further student protests. Respondents commented on the passive role they believed that UCT had adopted: 'A lot of children were killed in the 1976 Soweto riots. We put together a statement, but I think because of the atmosphere at UCT, no-one wanted to stand up and read it at a mass meeting. The other was the death of Steve Biko. UCT's response was poor. It made us see that UCT paid lip service. It wasn't interested in doing anything active.'

In 1980 black students decided to boycott classes in solidarity with an ongoing schools' boycott, including the final-year dinner and the graduation ceremony. A separate class photograph was organised: 'Graduation - we didn't feel like being part of it. Most didn't go. I went for my parents. We had separate photographs - it was our way of protesting.'

\section{Discussion}

The findings suggest that racism at UCT Medical School was entrenched through explicit policies and implicit rules adhered to by most students and staff. Black students were disallowed access to white patients and wards. Apartheid legislation was seemingly openly upheld by many UCT staff members. Intangible forms of social exclusion functioned as an equally - if not more - powerful means of re-enforcing discrimination. This survey underlines the importance of changing institutional culture as a key strategy to address discrimination. . $^{1,3,4}$

Racist treatment-associated humiliation and blows to self-esteem have profound emotive impacts,,$^{14}$ which black alumni processed in different ways, depending on their social and personal resources. Racism, however, also had direct practical consequences for the respondents' careers through curtailment of opportunities for training.

Black alumni experiences are echoed in other narratives of racism: a black person must work harder than a white person to be seen to perform; those who are racist are not even aware of their racism; and that awards specific to a discriminated-against group were patronising and felt as a form of racist treatment. These observations remain relevant in post-apartheid SA in the discourse on diversity in health sciences education. ${ }^{15}$

Findings suggest that although UCT was perceived as a liberal university with some staff members active in opposition to apartheid, ${ }^{1}$ it was not isolated from the discriminatory practices and values that typified SA society under apartheid. The disjunction between respondents' perception of an institution with staff espousing openly racist views, or at least being tacitly tolerant of racial discrimination on the one hand, and staff who intervened on behalf of black students on the other, is a striking feature of the findings from this survey.

Several implications emerge. Firstly, the duality of an institutional identity - both positive (resisting apartheid) and negative (colluding with apartheid) - must be acknowledged in achieving some form of reconciliation and healing of past divisions. ${ }^{2,6}$ The fact that black alumni can be bitterly angry at the treatment they received and feel 'cheated' in their life chances, yet recognise the quality of their training and admit to a sense of pride in the institution, affords opportunity to engage in redress. The fact that white staff's opposition to apartheid was invisible to respondents emphasises the importance of social engagement for justice and human rights being explicit in health professional curricula. ${ }^{2,4,16}$ If students do not witness active anti-racism, their experiences of discrimination are exacerbated.

Black alumni perceived most white staff and students as passive about, or indifferent to, the plight of black students. Social exclusion was the hallmark of respondents' experiences while studying at UCT. Recent research among black postgraduates in the Faculty confirms the tenaciousness of race in determining whether a student feels 'at home' in the learning environment. ${ }^{17}$

Another important factor that emerged is structural and cultural forces in internalising racism. Respondents adhered to rules without coercion, in a sense 'taking on' their own oppression. This is common in racist societies, often exacerbating the psychological harm of racist treatment; ${ }^{18}$ this emphasises the importance of agency for those experiencing discrimination to change the 'rules' that allow racist acts to continue. Challenging racism in medical training means, therefore, providing an institutional environment that enables meaningful action. ${ }^{2,14,17}$

Findings have provided the basis for transformation initiatives in the Faculty, ${ }^{6}$ aimed at creating a culture of human rights based on respect for human dignity and non-discrimination, and interventions to enhance the diversity of the learning and research environment. Moreover, they contribute to advancing a broader understanding of racial discrimination in health sciences education.

\section{Conclusions}

Reflecting on the past is necessary to effect changes to teaching and learning that produce graduates committed to a reconstructed society based on social justice and respect for human dignity. ${ }^{1,2,4}$ Unless we understand why and how discrimination was allowed to be 'normalised' in the past, and provide structures to support students and staff in addressing issues of racial and other forms of diversity, we risk a recurrence of similar injustice. Even within a climate of greater awareness, transformation of deep cultural practices within institutions and broader society presents challenges to the training of health professionals. Seeking not to attribute blame, but rather to understand how prejudice can become normalised, is key to creating a learning environment that values diversity and affirms the dignity of all people.

Terminology. In this paper, race is used as a social construct, to characterise identities imposed and replicated under apartheid. In using the terms 'white,' 'black', 'African', 'Indian' and 'coloured' there is no intention to legitimise their use, but to denote groups defined by the former race classification legislation which determined social status, access to societal resources and freedoms.

Acknowledgements. The authors wish to thank Ms Ayesha Fakie who assisted with data collection, Prof David Dent and Ms Phyllis Orner who helped with editing, and the many alumni who willingly shared their experiences for this study. Funding was provided by a grant from the National Research Foundation of South Africa.

\section{References}

1. Baldwin-Ragaven, L, de Gruchy J, London L. An Ambulance of the Wrong Colour. Health Professionals, Human Rights and Ethics in South Africa. Cape Town: UCT Press, 1999. 
Baldwin-Ragavan L, London L, de Gruchy J. Learning from our apartheid past: Human rights challenges

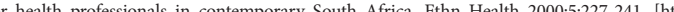
rg/10.1080/713667460]

3. Goodman T, Price M. Using an internal reconciliation commission to facilitate transformation at a health sciences faculty in post-apartheid South Africa: the case of the University of Witwatersrand Health Sciences Faculty. Health Hum Rights 2002;6: 211-227.

4. London L, Baldwin-Ragaven L. Human rights and health: Challenges for training nurses in South Africa. Curationis 2008;31:5-18.

5. Truth and Reconciliation Commission. Truth and Reconciliation Commission of South Africa Report, Volume 1. Cape Town: CTP Book Printers, 1998.

6. London L, Perez G. Reconciliation in the UCT Health Sciences Faculty: A vision for transformation. (personal view). S Afr Med J 2001;91:1027-1028.

Phillips H. University of Cape Town 1919-1948. The Formative Years. Cape Town: University of Cape Town Press, 1993.

8. Lawrence R. The Training of the Professional Man in South Africa. NUSAS Conference, Johannesburg,

9. Tobias PV. Apartheid and medical education: The training of black doctors in South Africa. J Natl Medical Assoc 1980;72:395-410

Saunders S. Vice Chancellor on a Tight Rope - A Personal Account of Climatic Years in South Africa Cape Town: David Philip Publishers, 2000.
11. Perez G, London L. "Forty-five years apart": Confronting the legacy of racial discrimination at the University of Cape Town. S Afr Med J 2004;94:764-770.

12. Strauss A, Corbin J. Basics of Qualitative Research. Grounded Theory Procedures and Techniques. California: Sage Publications, 1990

13. Krefting L. Rigor in Qualitative Research: The Assessment of Trustworthiness. The American Journal of Occupational Therapy 1991;45:214-222.

Occupational Therapy 1991;45:214-222.
Coker, N, ed. Racism in Medicine, An Agenda for Change. London: Kings Fund Publishing, 2001.

14. Coker, N, ed. Racism in Medicine, An Agenda for Change. London: Kings Fund Publishing, 2001.
15. London L, Ismail S, Alperstein M, Baqwa D. Diversity in the learning environment and curriculum reforn . London L, Ismail S, Alperstein M, Baqwa D. Diversity in the learning environment and curriculum reform
in the health sciences - challenges for a country in transition. Perspectives in Education 2002;20:21-32. 16. London L, Heap M, Baldwin-Ragaven L. Health and Human Rights: New challenges for socia responsiveness. Gateways: International Journal of Community Research and Engagement 2009;2:61-81. 17. Serote AC. Blackness in a predominantly white academe: the case of the University of Cape Town Faculty of Health Sciences. PhD thesis, University of Cape Town, 2011.

18. Speight SL. Internalised racism: One more piece of the puzzle. The Counseling Psychologist 2007;35:126134. [http://dx.doi.org/10.1177/0011000006295119]

Accepted 15 March 2012

\section{The UCT Faculty of Health Sciences Charter}

The Faculty adopted a Faculty Charter on 9 May 2002 as part of a process of recognising past discrimination, and instituting a reconciliation process. The Charter serves as a guide to much of the transformation work undertaken in the Faculty, and is intended to indicate the inclusiveness of the academic and social environment we hope to foster, where all individuals are able to realise their potential in the Faculty.

\section{Preamble}

Post-apartheid South Africa is emerging from decades of systematic discrimination that affected every aspect of society, including the health sector, resulting in profound inequities in health status in the population. Central to the reconstruction of South African society is the need to develop a culture of human rights based on respect for human dignity and nondiscrimination.

Although there were significant attempts by staff, students and the institution to resist apartheid injustices, UCT was not immune to the racist, sexist, and other discriminatory practices and values that typified society under apartheid. As UCT grapples with transformation, we remain with the legacy of these discriminatory practices.

To overcome this legacy of apartheid and other forms of discrimination, UCT Health Sciences Faculty is producing this Charter as a basis for transformation of the institutional culture of the faculty to ensure that students and staff have access to an environment where they are able to realise their full potential and become active participants in the academic life of the Faculty.

\section{Principles}

Non-discrimination

The Faculty will not tolerate any form of negative discrimination and will uphold the university's policy on non-discrimination.

\section{Supportive culture}

The Faculty will foster a supportive culture, where diversity and difference is respected, in order to encourage students and staff to reach their full potential in their activities of learning, working, teaching, research and service in the Faculty.

\section{Capacity building}

The Faculty will strive to develop the skills of its employees and help to build the skills base of South Africans, in particular formerly disadvantaged South Africans, through various strategies at its disposal.

\section{Employment equity}

The Faculty will strive to attract and retain talented black professionals by recognising their abilities, affirming their skills and ensuring an environment that is welcoming and supportive.

\section{Facilitation of learning}

The Faculty will strive to uphold and encourage the highest standards of teaching, and strive to create an atmosphere conducive to learning for all students.

\section{Research}

The Faculty will strive to uphold the highest ethical standards of research and ensure that research seeks to benefit the South African community.

\section{Service}

The Faculty will strive to ensure that students and staff uphold the highest standards of service to the community, including commitments to ethical principles and human rights.

\section{Consultation}

The Faculty will strive to consult with staff and students on major policy changes that affect them that may be undertaken by the Faculty and seek to entrench transparency in its workings.

\section{Monitoring and evaluation}

The Faculty will endeavour to annually review its performance in the light of this Charter.

\section{Community participation}

The Faculty will strive to ensure participation of the community in decisions in the spirit of the Primary Health Care Approach adopted by the Faculty as its lead theme. 